\title{
PROCESSO DE EXTRAÇÃO DAS PROTEÍNAS DE SORO DE LEITE PARA PRODUÇÃO DE CONCENTRADO PROTEICO
}

\section{Resumo}

O soro de leite, obtido como subproduto durante o processamento de queijos e gerado em larga escala em laticínios, possui elevado valor nutricional decorrente de sua composição de proteínas de alto valor biológico, aminoácidos essenciais e de cadeia ramificada. O método de extração das proteínas de soro de leite mais utilizado é a ultrafiltração, sendo um processo de separação do soro em que a água e os solutos são removidos pela passagem por uma membrana semipermeável, resultando na concentração das proteínas de soro de leite. A metodologia utilizada na elaboração deste artigo consistiu em revisão bibliográfica, sendo levantados dados sobre o tema por meio de livros, artigos nacionais e internacionais, impressos e online, dissertações de mestrado e teses de doutorado. O impacto ambiental gerado pelo descarte incorreto deste subproduto tem levado à utilização dos concentrados proteicos também chamados de whey protein, para produção de suplementos alimentares de uso esportivo. A funcionalidade tecnológica dessas proteínas também possibilita seu uso pelas indústrias de alimentos como matéria-prima para formulações de produtos, dada sua capacidade absortiva, elástica, gelificante, emulsionante e outras propriedades funcionais.

Palavras-chave: Proteínas de soro de leite. Ultrafiltração. Concentrado proteico. 


\section{INTRODUÇÃO}

O leite é caracterizado por uma emulsão cremosa composta por glóbulos de gordura em fase aquosa, de forma que seus ingredientes, como glóbulos de caseína, proteínas, lactose e sais, encontram-se suspensos e dissolvidos (ALLESSI; ARCHER; CLARO, 2005).

O soro do leite é um subproduto resultante da fabricação de queijos pela fermentação do leite através de ação bacteriana ou ainda pela ação de agentes coagulantes, cujas proteínas possuem elevado teor nutricional e tecnológico, atraindo o interesse das indústrias alimentícias em sua utilização como matéria-prima para fabricação de diversos produtos, entre eles os concentrados proteicos.

$\mathrm{Na}$ produção de queijos, a obtenção de soro de leite pode chegar de $80 \%$ a $90 \%$ do volume de leite utilizado (PEREIRA, 2009).

Os concentrados proteicos obtidos através da extração das proteínas do soro de leite possuem alto valor nutricional, além de elevado teor de aminoácidos essenciais e de cadeia ramificada, cálcio e peptídeos bioativos do soro, justificando sua ampla utilização como suplemento alimentar, conhecido no meio esportivo pela nomenclatura whey protein (PEREIRA; LAJOLO; HIRSCHBRUCH, 2003; ALBINO; CAMPOS; MARTINS, 2009; LOLLO; TAVARES, 2004).

Estes concentrados proteicos também apresentam capacidade de solubilidade em uma larga escala de $\mathrm{pH}$, ação gelificante, propriedades de retenção de água, ação emulsionante e capacidade de formação de espumas. Tais propriedades abrem um leque de aplicação das proteínas de soro de leite nas indústrias de alimentos, fármacos e de biotecnologia (PEREIRA, 2009).

Em virtude das múltiplas possibilidades de aplicação do soro de leite como concentrado proteico, este estudo tem como objetivo co- $^{-}$ nhecer o processo para extração das proteínas concentradas do soro de leite, os equipamentos utilizados e a aplicação destes concentrados proteicos na indústria de alimentos.

\section{CONCENTRADOS PROTEICOS E A INDÚSTRIA DE ALIMENTOS}

A indústria de alimentos é um setor que se encontra em constante desenvolvimento e expansão no Brasil e no mundo. A criação de novos produtos, incentivada por um mercado consumidor exigente, envolve a utilização de processos, equipamentos e tecnologias cada vez mais inovadores (GUEDES, 2012).

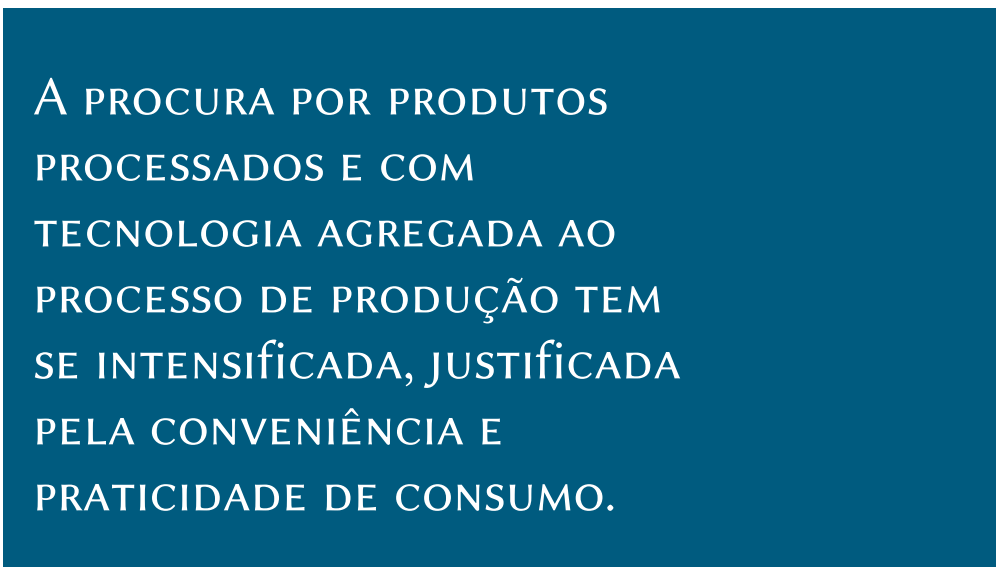


Além disso, o mercado consumidor tem buscado produtos voltados à saúde e à estética corporal. Neste sentido, as indústrias de alimentos estão investindo na fabricação de produtos diferenciados, como os concentrados proteicos obtidos através da extração das proteínas de soro de leite, ou whey protein, que estão entre os produtos que apresentam crescentes demandas (BIESEK; ALVES; GUERRA, 2005; MAUGHAN; BURKE, 2004).

A extração do soro de leite na indústria de alimentos pode ser realizada através de três processos principais: coagulação enzimática das caseínas para produção de queijos e soro doce; precipitação ácida no $\mathrm{pH}$ isoelétrico, resultando em caseinatos e soro ácido; e separação das micelas de caseína por ultrafiltração, para obtenção de concentrados ou isolados proteicos (SGARBIERI, 2004).

O concentrado proteico de soro de leite obtido através do processo de ultrafiltração possui proteínas de alto valor biológico, justificando sua utilização em larga escala como matéria-prima naindústria de alimentos, assim como em razão de suas propriedades funcionais, nutracêuticas e tecnológicas, úteis tanto na produção de suplementos alimentares como pela sua capacidade de formar espumas, emulsões e géis (PEREIRA, 2009).

\subsection{Leite}

Oleite éum fluido composto por água, minerais em forma de solução iônica, lactose, albumina, caseína, fosfatos e gordura, constituindo uma emulsão, de forma que a gordura e a água estão estabilizadas por uma dispersão de proteínas em uma solução de sais, vitaminas, peptídeos e outros componentes menores. Seu pH oscila entre 6,5 a 6,7, de acordo com a temperatura, diminuindo com o aumento da mesma (GUEDES, 2012).

Em sua fase líquida, o leite apresenta partículas suspensas de gordura e micelas de caseína. Sua forma de comercialização nesta fase pode ser integral ou desengordurada, ou ainda na forma desidratada, como o exemplo do leite em pó (SGARBIERI, 2004). A composição química do leite de vaca integral é apresentada na Tabela 01.

Tabela 1: Composição média do leite de vaca integral

\begin{tabular}{cc} 
Constituinte & Teor $\mathbf{( g / \mathbf { 1 0 0 } )}$ \\
Água & 87,1 \\
Lactose & 4,6 \\
Gordura & 4,0 \\
Proteínas & 3,25 \\
Caseína & 2,6 \\
Minerais & 0,7 \\
Ácidos orgânicos & 0,17 \\
Outros & 0,15 \\
\hline
\end{tabular}

Fonte: Adaptado de Guedes (2012) 


\subsection{Soro de leite}

O soro de leite é um líquido remanescente da precipitação e remoção da caseína do leite. Em sua composição, encontra-se em maior proporção a lactose (4,5\%-5,0\%), além de proteínas solúveis $(0,6 \%-0,8 \%)$,lipídios $(0,4 \%-0,5 \%)$, sais minerais (8,0\%-10,0\%) e água, cujo percentual chega a atingir 93\%. Essa composição está sujeita a variações, de acordo com o método de separação da caseína, podendo-se obter soro ácido e soro doce (BIASUTTI, 2006).

O soro doce é o tipo mais comumente utilizado na alimentação.É produzido pela inoculação do leite com cultura de bactérias láticas e apresenta $\mathrm{pH}$ de 6,2 a 6,4, enquanto que o soro ácido é originado pela coagulação da caseína, que passa por corte e aquecimento, seguido de drenagem, apresentando $\mathrm{pH}$ entre 4,5 e 4,8. O sabor ácido limita seu uso na alimentação (AIRES, 2010).

No aspecto nutricional, o soro de leite apresenta alto teor de aminoácidos essenciais, componentes estes que necessitam ser obtidos exclusivamente através da alimentação, por não serem sintetizados pelo organismo humano. Entre eles estão a lisina, treonina, triptofano, fenilalanina, tirosina e lactalbumina (OLIVEIRA; BRAVO; TONIAL, 2012).

\subsection{Proteínas de soro de leite}

Durante vários anos, o soro de leite foi desprezado pela indústria alimentícia. Somente a partir da década de 70, as propriedades das proteínas extraídas do soro de leite começaram a ser estudadas pela ciência (HARAGUCHI; ABREU; PAULA, 2006).
As proteínas do soro de leite apresentam estrutura globular contendo pontes de dissulfeto e são compostas por $70 \%$ a $80 \%$ de $\alpha$-lactoalbumina e ß-lactoglobulina, sendo o restante composto por imunoglobulinas, albumina do soro bovino, lactoferrina, lactoperoxidase e glicomacropeptídeo. Seu valor nutricional excede ao de outras proteínas alimentícias, tais como ovos, queijos, carnes, peixes e soja (PASSOTTO, 2012; PEREIRA, 2009).

A a-lactoalbumina representa 15 a $20 \%$ da proteínas do soro de leite. Contém $123 \mathrm{ami-}$ noácidos e, quando purificada, é utilizada para fabricação de fórmulas infantis em decorrência de sua similaridade com a principal proteína do leite materno, tanto em composição como em estrutura.

\section{É USADA TAMBÉM COMO \\ INGREDIENTE NA PRODUÇÃO DE \\ SUPLEMENTOS PROTEICOS PARA \\ ATLETAS, POR SUA VASTA COM- \\ POSIÇÃO DE AMINOÁCIDOS DE \\ CADEIA RAMIfiCADA, ATUANDO \\ NA GERAÇÃO DE ENERGIA E NA \\ SÍNTESE MUSCULAR PROTEICA \\ (LEINDECKER, 2011).}

A ß-lactoglobulina corresponde a 50\% das proteínas do soro. É composta por 162 aminoácidos e possui em sua estrutura um grupo tiollivre, podendo associar-se a outras proteínas hidrofóbicas, além de duas pontes dissulfeto. A ß-lactoglobulina apresenta leucina em sua composição, um aminoácido essencial ativador de proteínas celulares envolvidas na síntese de proteína muscular (HARAGUCHI, 2011). 


\subsection{Processo de extração de proteínas de soro de leite: ultrafiltração}

O processo mais utilizado para obtenção de proteínas concentradas de soro de leite chama-se ultrafiltração, um processo de separação que utiliza membranas com poros de tamanhos maiores, permitindo assim a passagem de sais e moléculas de açúcar. $\mathrm{O}$ soro pode ser separado em duas frações, para formação de concentrados proteicos ou de isolados proteicos. O concentrado proteico possui em sua composição de 35 a 80\% de proteínas, enquanto o isolado apresenta mais de $90 \%$ de proteína em sua composição (PEREIRA, 2009).

A ultrafiltração é uma operação na qual água e alguns solutos em uma solução são removidos seletivamente por uma membrana semipermeável. Essa técnica consiste em um processo de pressão utilizada para purificar, separar e concentrar materiais de alto peso molecular em solução. Sua utilização é economicamente viável e, por não utilizar calor e não envolver mudança de fase, pode ser amplamente utilizada pela indústria de alimentos, sem perda dos nutrientes presentes no soro. A ultrafiltração aumenta a qualidade microbiológica do leite, pela diminuição da contagem de esporos no concentrado (BALDASSO, 2008).

A ultrafiltração de concentrado de soro de leite, além de concentrar proteínas, permite a permeação dos componentes de baixa massa molecular, como lactose, minerais, nitrogênio não proteico e vitaminas. $\mathrm{O}$ soro, ao ser processado por ultrafiltração, gera entre 50 e 75\%, em base seca, de proteína no retentado, que poderá ser posteriormente liofilizado, sendo o retentado definido como o produto retido durante o processo de filtração, também chamado de concentrado. Na indústria alimentícia, a ultrafiltração tem sido utilizada, entre outras aplicações, para recuperar ingredientes de valor nutricional (SOUZA, 2010). A Figura 01 mostra um ultrafiltrador.

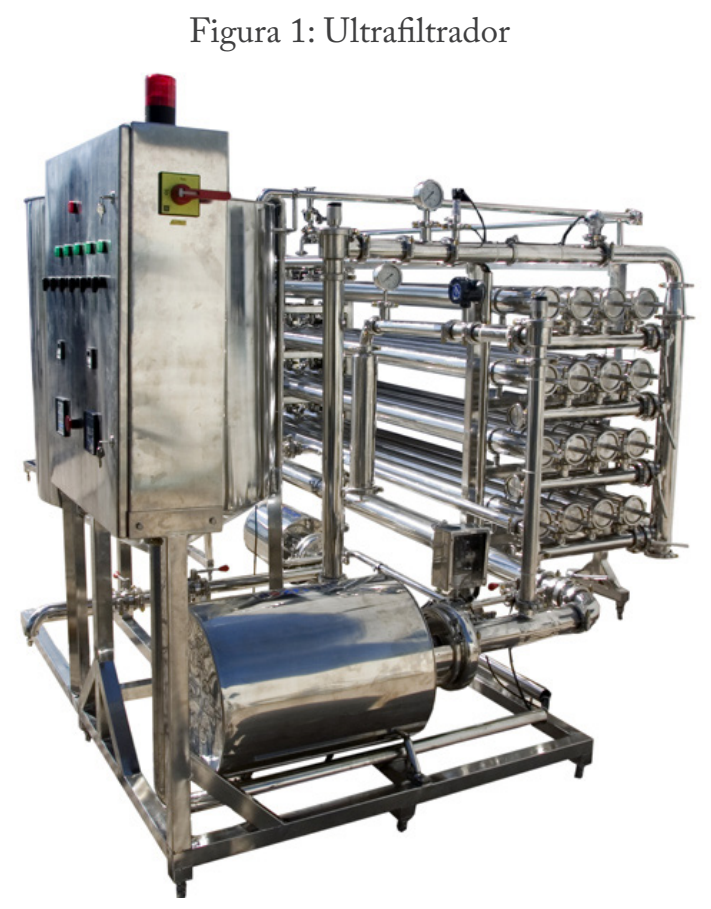

Fonte: EJ Máquinas (2015)
De acordo com Boschi (2006), o processo de ultrafiltração pode ser projetado para operar em batelada ou em processo contínuo, sendo a operação contínua a mais adequada para processos em larga escala.

O processamento por bateladas, ou lotes, é definido como um método industrial que prioritariamente programa curtos ciclos de fabricação de produtos, enquanto que no processo contínuo não há existência de interrupções. 


\subsection{Etapa de secagem do concentrado proteico}

Após a etapa de ultrafiltração, o concentrado proteico precisa passar pela etapa de secagem. Para esta etapa, o sistema mais utilizado nas principais áreas de processamento de soro de leite tem sido o spray dryer. A secagem do soro de leite é semelhante ao processo para obtenção de leite em pó (AIRES, 2010).

No secador atomizador, ou spray dryer, o processo de secagem é dividido em três etapas. $\mathrm{Na}$ primeira, soro de leite é disperso em pequenas gotas, originando uma grande área de superfície. Após esta etapa, as gotículas entram em contato com uma corrente de ar quente, possibilitando transferência de calor. Em seguida, ocorre uma rápida evaporação e consequente formação de partículas sólidas(OLIVEIRA;PETROVICK, 2010).

A utilização da secagem por nebulização ou atomização, mais conhecida pela indústria por spray drying, tem se aplicado em larga escala na fabricação de produtos das linhas alimentícia e farmacêutica. O spray dryer tornou-se o equipamento mais utilizado para a secagem de materiais que apresentam sensibilidade ao calor, como alimentos e materiais de origem biológica, dentre eles as proteínas (ROSA; TSUKADA; FREITAS, 2006). A Figura 02 apresenta o esquema de um sistema spray dryer.

Figura 2: Sistema spray dryer

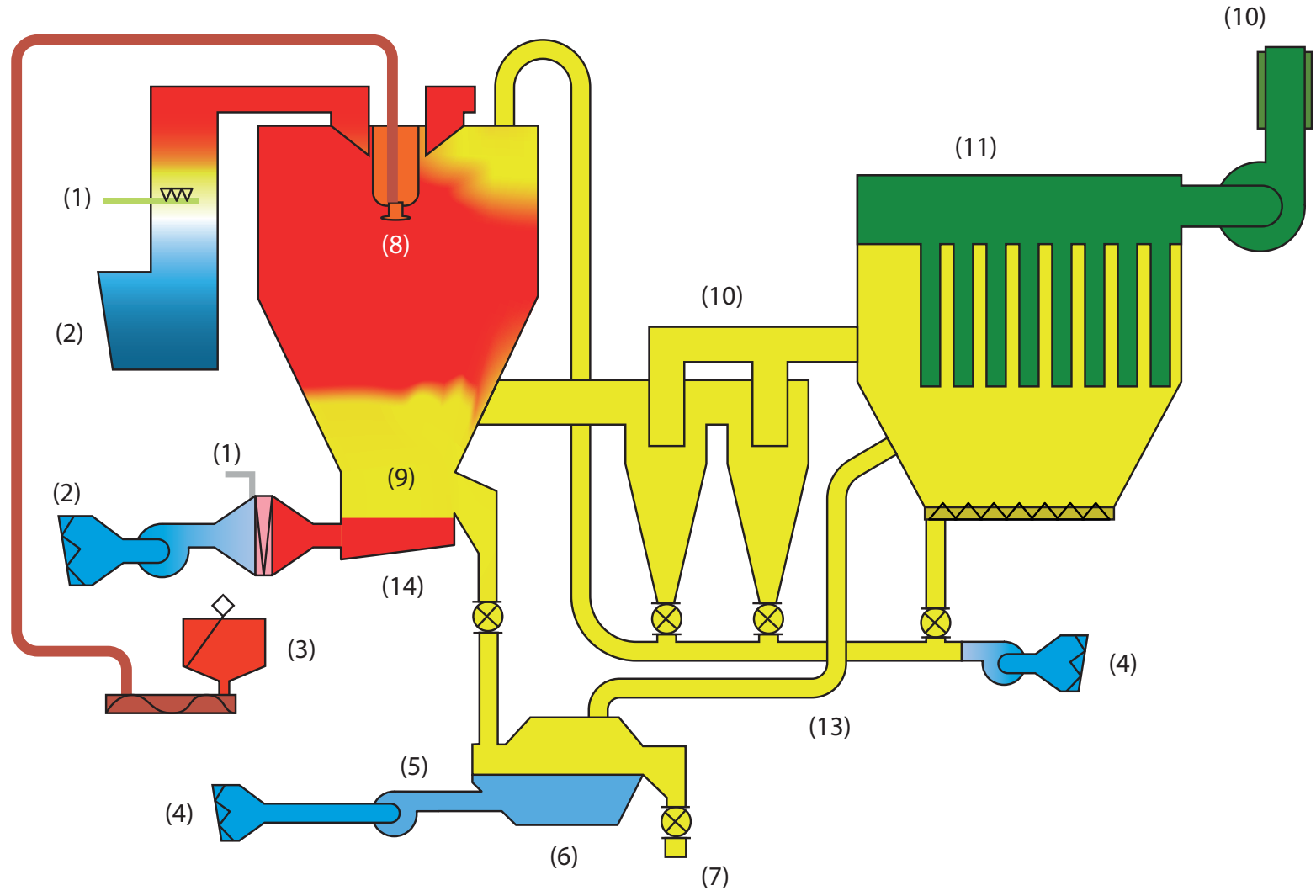
(1) Ar quente;
(2) Entrada de ar;
(3) Bomba de alimentação;
(4) Introdução de ar para resfriamento do produto;
(5) Produto seco frio;
(6) Leito fluidizado;
(7) Produto final seco;
(8) Bico de atomização-spray;
(9) Câmara de Produto atomizado (névoa);
(10) Ciclone de recuperação;
(11) Filtro de ar invertido;
(12) Saída de ar;
(13) Produto recuperado;
(14) Leito fluidizado de aglomeração.

Fonte: Adaptado de Rosa, Tsukada e Freitas (2006) 
Além da secagem por spray dryer, a liofilização também pode ser utilizada como método de secagem após a ultrafiltração do soro de leite. A liofilização, ou secagem por congelamento, consiste em um processo de retirada de água por sublimação, de forma que a água passa diretamente do estado sólido para o gasoso, sem passar pelo estado líquido. Para a sublimação ocorrer, é necessário que o alimento seja congelado a $-40^{\circ} \mathrm{C}$ e que as condições de pressão sejam controladas, utilizando-se para isto câmaras herméticas de alto vácuo (ROSA; TSUKADA; FREITAS, 2006). A Figura 03 representa o sistema de secagem por liofilização.

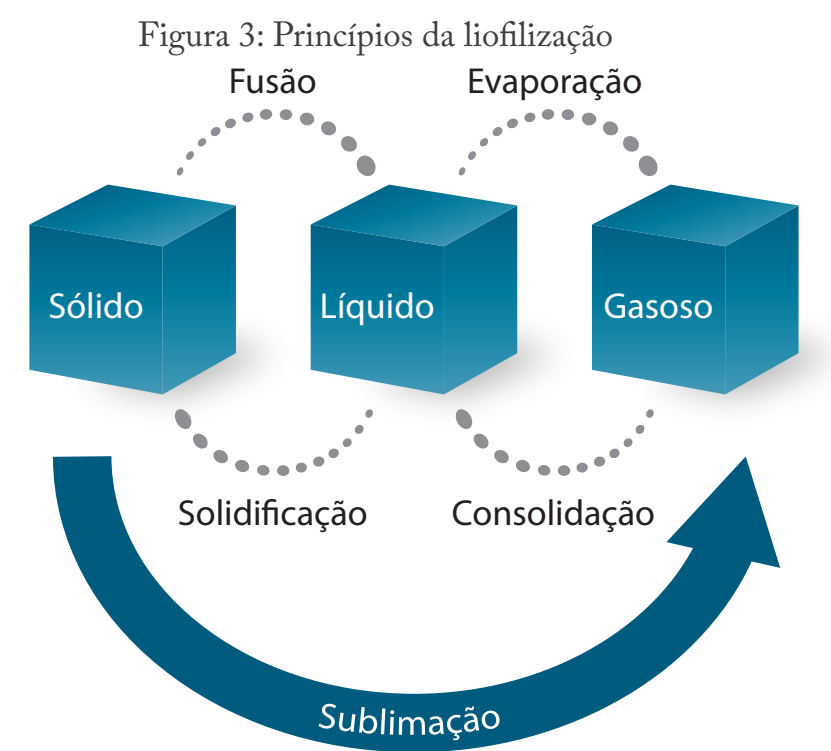

Fonte: Liotécnica Tecnologia de Alimentos Ltda. (2015)

A liofilização permite a desidratação do soro de leite sem exposição a altas temperaturas. Como vantagem deste método, está a manutenção do valor nutricionale das características sensoriais e organolépticas, como textura,forma,cor, sabor e odor.Também são disponibilizados ao mercado consumidor produtos estáveis e seguros, pela diminuição da atividade de água (aw), principal meio de desenvolvimento de microrganismos, proporcionando assim estabilidade microbiológica (VIEIRA; NICOLETI; TELIS,2012).

\section{A VANTAGEM DO MÉTODO \\ SPRAY DRYER SOBRE A \\ LIOfILIZAÇÃO CONSISTE NO CUSTO.}

A liofilização exige investimentos maiores em equipamentos e operacional, apresentando menor produtividade em relação ao spray dryer. É recomendada a avaliação da aplicabilidade de ambos os métodos (ROSA; TSUKADA; FREITAS, 2006).

\subsection{Soro de leite e meio ambiente}

Por muitos anos, o soro de leite foi desprezado pela indústria alimentícia. Este subproduto era utilizado apenas para fabricação de ração animal, ou então descartado diretamente no meio ambiente.Porém, por ser altamente poluente em virtude de sua carga material orgânica elevada, 
seu descarte nos efluentes pode acarretar em impactos ambientais críticos, o que levou a indústria a estudar maneiras de utilização do soro de leite como matéria-prima para formulação de diversos produtos, contribuindo com a minimização dos impactos ambientes de seu descarte incorreto (HARAGUCHI, 2011; OLIVEIRA; BRAVO; TONIAL, 2012).

De acordo com Pacheco et al. (2005), foi somente a partir da década de 70 que os cientistas iniciaram os estudos sobre os métodos de preparo e utilização das proteínas de soro de leite. A finalidade destes estudos foi tanto clínica e nutricional como funcional, abordando as formas de uso pela indústria de alimentos como maneira de aproveitar este valioso subproduto, produzido em quantidades generosas nas indústrias queijeiras. Estima-se que a cada quilo de queijo produzido sejam gerados nove quilos de soro deleite(OLIVEIRA;BRAVO;TONIAL, 2012).

A lactose e as proteínas constituintes do soro de leite requerem alto valor de demanda biológica de oxigênio para o tratamento dos efluentes residuais, tornando este processo não viável para as indústrias. A qualidade biológica das proteínas de soro de leite tem levado à avaliação de uma série de medidas de reaproveitamento deste subproduto, com vistas a melhorias na eficiência econômica dos laticínios e à diminuição dos impactos ambientais (ALLESSI; ARCHER; CLARO, 2005).

\subsection{Concentrados proteicos para fabricação de suplementos alimentares}

Uma das formas encontradas pela indústria de alimentos para reaproveitamento das proteínas de soro de leite é a produção de suplementos alimentares. Os suplementos alimentares são definidos pela ANVISA como alimentos especialmente formulados para auxiliar os atletas a atender às suas necessidades nutricionais específicas e contribuir na melhora do desempenho do exercício. Sua indicação é realizada quando há uma necessidade aumentada de nutrientes, ou ainda quando o atleta não disponibiliza tempo para alimentar-se adequadamente. Inclui-se nesta classe de suplementos os concentrados proteicos (BRASIL，2010; FERREIRA, 2009).

Os suplementos proteicos, classe na qual se enquadram as proteínas do soro de leite, ou whey protein, são considerados produtos destinados a complementar as necessidades proteicas e precisam seguir parâmetros específicos em sua composição. Devem conter, no mínimo, $10 \mathrm{~g}$ de proteína na porção e 50\% do valor energético total proveniente das proteínas, e a composição proteica do produto deve apresentar PDCAAS acima de 0,9, cuja determinação deve estar de acordo com a metodologia de avaliação recomendada pela Organização das Nações Unidas para Agricultura e Alimentação/Organização Mundial da Saúde(FAO/WHO).OPDCAAS corresponde ao escore aminoacídico corrigido pela digestibilidade da proteína para a determinação de sua qualidade biológica (BRASIL, 2010).

Os efeitos fisiológicos ocasionados pelo consumo de concentrados proteicos de soro de leite, ou whey protein, são resultado do aumento da síntese muscular proteica, que ocorre simultaneamente à redução da gordura corporal, em consequência do alto teor de cálcio e glutationa presentes no soro de leite, que favorecem a diminuição da ação de oxidantes nos músculos esqueléticos e o aumento da concentração insulínica no plasma sanguíneo, facilitando assim a captação de aminoácidos para o interior 
das células musculares (ALVES; LIMA, 2009; CEZAR et al.,2012; ZEISER; SILVA, 2007).

As proteínas do soro de leite também são conhecidas por trazer benefícios ao estado de saúde geral. Entre suas funções, destacamse reparo celular, muscular e ósseo; atividade imunomoduladora, antibacteriana e antiviral através da produção de glutationa, substrato essencial do sistema imunológico; proteção do sistema cardiovascular, pela inibição da agregação plaquetária, que traz como consequência a redução na pressão arterial e nos níveis de colesterol sanguíneo, pela liberação de peptídeos de ação hipotensora e anti-hipertensiva (ALMEIDA et al., 2013).

Outras condições patológicas também demonstraram ter sido atenuadas pelo consumo das proteínas de soro de leite. Foi observada ação protetora pela inibição de diversos tumores, como câncer de mama e de próstata, câncer hepático e leucemia. A ação antitumoral ocorre através da produção da glutationa, do estímulo aos linfócitos e da síntese de imunoglobulina, além da produção e propagação de antioxidantes que atuam na proteção ao DNA através da neutralização de agentes tóxicos e substâncias pró-carcinogênicas (ZIEGLER et al., 2012).

\subsection{Outras aplicações do soro de leite pela indústria de alimentos}

Alternativas para a utilização dos concentrados proteicos provenientes do soro de leite são imprescindíveis, visto o volume de produção do soro de leite pelas indústrias lácteas, seu valioso teor nutritivo e os impactos ambientais ocasionados pelo seu descarte incorreto. Sua versatilidade possibilita seu uso como matéria-prima de formulações, assim como ingrediente para a fabricação de produtos alimentícios (MARQUES et al., 2005).

Uma das opções encontradas para o uso do soro de leite é na produção de bebidas lácteas, uma das maneiras mais utilizadas no Brasil para aproveitamento deste derivado lácteo, sendo usado para a fabricação tanto de bebidas fermentadas, com características sensoriais semelhantes ao iogurte, como não fermentadas (BIASUTTI, 2006).

AS PROTEÍNAS DO SORO DE

LEITE TAMBÉM SÃO UTILIZADAS

COMO INGREDIENTE NA

FORMULAÇÃO DE ALIMENTOS

INFANTIS E NA COMPOSIÇÃO

DE FÓRMULAS ENTERAIS,

AUXILIANDO NO AUMENTO DE

PESO DE FORMA SAUDÁVEL EM

PACIENTES PÓS-CIRÚRGICOS,

ACAMADOS E IDOSOS DE BAIXO

PESO (CAPITANI ET AL., 2005).

As excelentes propriedades funcionais e aromáticas das proteínas do soro de leite propiciam ainda sua utilização na fabricação de ricota, queijos e doce de leite, além de produtos para a indústria, como proteína de soro, creme de soro, lactose, minerais do leite e novos produtos, como filmes transparentes comestíveis feitos com isolados proteicos (OLIVEIRA; BRAVO; TONIAL, 2012). Aversatilidade dos concentrados proteicos permite ainda seu uso pela indústria alimentícia em aplicações muito diversificadas, conforme pode ser observado na Tabela 02. 
Tabela 2: Propriedades funcionais dos concentrados proteicos e sua aplicabilidade pela indústria alimentícia

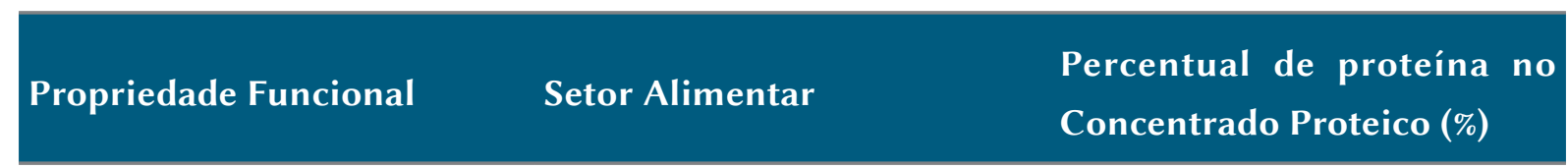

\begin{tabular}{ccc} 
Viscosidade & Sobremesas & 35 \\
\hline $\begin{array}{c}\text { Solubilidade, estabilidade } \\
\text { coloidal }\end{array}$ & Bebidas & 35 \\
\hline Emulsificação & $\begin{array}{c}\text { Café, sopas, alimentos } \\
\text { infantis }\end{array}$ & 85 \\
\hline Formação de espumas & Confeitaria & 35 \\
\hline Geleificação & Produtos lácteos & 65 \\
\hline Elasticidade & Panificação & 65 \\
\hline Coesão e adesão & Produtos em pasta & 85 \\
\hline Absorção de água e gordura & Produtos carneos & 85 \\
\hline
\end{tabular}

Fonte: Adaptado de Baldasso (2008)

Os atributos funcionais e a utilização dos concentrados proteicos de soro de leite em produtos acabados estão relacionados à característica da fração proteica. Os concentrados proteicos são mais solúveis que a própria caseína, a proteína primária encontrada no leite, presente em $80 \%$ do conteúdo proteico total. Desta forma, os concentrados proteicos podem ser usados na produção de diet shake e bebidas energéticas, e seu grau de solubilidade e funcionalidade podem ser aumentados pela hidrólise (PASSOTTO, 2012).
As propriedades funcionais dos concentrados proteicos de soro de leite ocorrem devido às interações dos compostos ligados à proteína, de forma que as propriedades dependentes da interação água-proteína são a absorção, coesão, adesão, solubilidade, estabilidade e viscosidade. A propriedade de geleificação está relacionada à interação proteína-proteína e às propriedades de superfície, que incluem a emulsificação, formação de espumas e elasticidade (GUEDES, 2012).

\section{CONCLUSÃO}

A excelente qualidade nutricional dos concentrados proteicos produzidos a partir das proteínas de soro de leite tem sido demonstrada por diversos estudos, assim como sua versatilidade funcional para uso como ingrediente pela indústria de alimentos.
A utilização deste subproduto evita severos impactos ambientais, que seriam ocasionados pelo seu descarte incorreto, além de visar ainda à melhoria econômica dos laticínios. 
A extração das proteínas de soro de leite pelo método de ultrafiltração, técnica que utiliza uma membrana semipermeável para realizar a separação do soro, seguido de secagem por atomização, ou liofilização, é adequada para a produção de concentrado proteico com composição de 35 a $80 \%$ de proteínas, podendo ser utilizado para fabricação de suplementos alimentares, bem como matéria-prima de formulações alimentícias. 


\section{PROCESS OF PROTEIN \\ WHEY EXTRACTION \\ FOR PROTEIN \\ CONCENTRATE \\ PRODUCTION}

ABSTRACT

Whey, obtained as abyproduct during cheeseprocessing and generated on a large-scale in dairy products, has bighnutritionalvalue due to itscomposition of proteins of high biological value, essential amino acids and branched chain. The most widely used method of whey protein extraction is ultrafiltration, a process of separating whey in which water and solutes are removed by passing through a semipermeable membrane, resulting in the concentration of whey protein. The methodology used in the preparation of this article consisted of a literature review, with data on the topic being collected in books, national and international printed and online articles, master's dissertations and doctoral theses. The environmental impact caused by incorrect disposal of that byproduct has led to the use of protein concentrates, also called whey protein, for production of food supplements for sporting use. Technological functionality of those proteins also enables their use by the food industry as a raw material for product formulations, as their absorptive, elastic, gelling, emulsifying capacities and other functional properties.

Keywords: Whey proteins.

Ultrafiltration. Protein

concentrate.

\section{REFERÊNCIAS}

AIRES, A. G. O soro de leite como suplemento proteico para atletas. 2010.52 p. Monografia Instituto de Ciência e Tecnologia de Alimentos, Curso de Engenharia de Alimentos, Porto Alegre, 2010.

ALBINO, C. S.; CAMPOS, P. E.; MARTINS, R. L. Avaliação do consumo de suplementos nutricionais em academias de Lages, SC. Rev. Digital. Buenos Aires, v. 14, n. 134, 2009.

Disponível em: <http://zip.net/bctx1b >. Acesso em: 13 jan. 2014.

ALLESSI, L. R.; ARCHER, M. A. B.; CLARO, $R$. P. Estudo de viabilidade técnica e econômica da extração das proteínas de soro de leite. 2005. 90 p. Monografia - Departamento Acadêmico de Mecânica, Centro Federal de Educação Tecnológica do Paraná, Curitiba. Disponível em: <https://goo.gl/ g3jbCU>. Acesso em: 13 dez. 2013.

ALMEIDA, C. C. et al. Proteína do soro do leite: composição e suas propriedades funcionais. Enciclopédia Biosfera, Goiânia, v. 9, n.16, p. 1840-1854, 2013. Disponível em: <http://zip.net/ bmtxWX>. Acesso em: 09 dez. 2013.

ALVES, C.; LIMA, R. V. B. Uso de suplementos alimentares por adolescentes. J. Pediatr. Porto Alegre, v. 85, n.4, p. 287-294, 2009. Disponível em: <http://zip.net/bjtxVy>. Acesso em: 13/01/2014.

BALDASSO, C. Concentração, purificação e fracionamento das proteínas do soro lácteo através da tecnologia de separação por membranas. 2008. 179 p. Dissertação de Mestrado - Departamento de Engenharia Química, Universidade Federal do Rio Grande do Sul, Porto Alegre. Disponível em: <http://zip.net/bstyhw>. Acesso em: 30 jun. 2014.

BIASUTTI, E. A. R. Otimização das condições da hidrólise enzimática das proteínas do soro de leite para obter elevado teor de oligopeptídeos: utilização da subtilisina e da pancreatina. 2006. 88 p. Dissertação de Mestrado - Programa de PósGraduação em Ciência de Alimentos da Faculdade de Farmácia, Universidade Federal de Minas Gerais. Disponível em: <http://zip.net/bgtxZs >. Acesso em: 13 dez. 2013.

BIESEK, S.; ALVES, L. A.; GUERRA, I. (Orgs.) Estratégias de nutrição e suplementação no esporte. 1. ed. São Paulo: Manole, 2005. 
BOSCHI, J. R. Concentração e purificação das proteínas do soro de queijo por ultrafiltração. 2006. 119 p. Dissertação de Mestrado - Programa de PósGraduação em Engenharia Química, Departamento de Engenharia Química, Universidade Federal do Rio Grande do Sul. Porto Alegre. Disponível em: <http:// zip.net/bvtyrW>. Acesso em: 27 jun. 2014.

BRASIL. Resolução RDC n. 18, de 27 de abril de 2010. Dispõe sobre alimentos para atletas. Diário Oficial [da] República Federativa do Brasil, Poder Executivo, Brasília, DF, 27 de Abril de 2010. Disponível em: <http://zip.net/bltxwj>. Acesso em: 13 jan. 2014.

CAPITANI, C. D. et al. Recuperação de proteínas do soro de leite por meio de conservação com polissacarídeo. Pesq. agropec. bras. [online], v.40, n.11, p. 1123-1128, 2005. Disponível em: < http://zip.net/ bdtywQ >. Acesso em: 09 dez. 2013.

CEZAR, F. R. et al. Whey Protein: proteína do soro do leite. EFDeportes.com, Revista Digital. Buenos Aires, v.17, n.167, 2012. Disponível em: <http://zip. net/bmtxWX>. Acesso em: 13 dez. 2013.

EJ MÁQUINAS. Ultrafiltração. 2015. Disponível em: <http://zip.net/bstyhx>. Acesso em: 27 jun. 2014.

FERREIRA, A. C. D. Suplementos alimentares: adequabilidade à legislação e efeitos metabólicos em ratos. 2009. Dissertação de mestrado apresentada ao Programa de Pós-Graduação em Ciências da Nutrição da Universidade Federal da Paraíba. João Pessoa, 2010.

GUEDES, P. V. Caracterização reológica e ultraestrutural de géis produzidos à base de caseinomacropeptídeo. 2012.135 p. Dissertação de Mestrado - Programa de Pós-Graduação em Engenharia de Alimentos, Setor de Tecnologia, Universidade Federal do Paraná, Curitiba. Disponível em: <http://zip.net/bptyH2>. Acesso em: 13 dez. 2013.

HARAGUCHI, F. K. Prevenção da oxidação tecidual e modificações na expressão gênica da m'Tor e MAFbx do músculo de ratos exercitados alimentados com as proteínas do soro do leite. 2011. 114 p. Tese de Doutorado - Programa de Pós-Graduação do Núcleo de Pesquisas em Ciências Biológicas (NUPEB), Universidade Federal de Ouro Preto, Ouro Preto. Disponível em: <http://zip.net/bytytp>. Acesso em: 01 jul. 2014.

HARAGUCHI, F. K.; ABREU, W. C.; PAULA, H. Proteínas do soro do leite: composição, propriedades nutricionais, aplicações no esporte e benefícios para a saúde humana. Rev. Nutr. [online], v.19, n.4, p. 479-488, 2006. Disponível em: <http://zip.net/bltxwk>. Acesso em: 09 dez. 2013.
LEINDECKER, G. C. Separação das proteínas do soro do leite in natura por ultrafiltração. Repositório Digital, LUME. 2011. Escola de Engenharia, Universidade Federal do Rio Grande do Sul, Porto Alegre. Disponível em: <http://zip.net/bttyMh>. Acesso em: 01 jul. 2014.

\section{LIOTÉCNICA TECNOLOGIA DE}

ALIMENTOS LTDA. 2015. Disponível em: <http:// zip.net/bptyH3>. Acesso em: 18 jul. 2014

LOLLO, P. C. B.; TAVARES, M. C. G. C. F. Perfil dos consumidores de suplementos dietéticos nas academias de ginástica de Campinas - SP. Rev. Digital, Buenos Aires, v. 10, n. 76, 2004. < Disponível em: <http://zip.net/bftxWh>. Acesso em: 13 jan. 2014.

MARQUES, D. P. et al. Separação das proteínas do soro do leite por deae-trisacryl. Alim. Nutr. Araraquara, v.16, n.1, p. 17-20, 2005. Disponível em: <http://zip.net/bstyhz>. Acesso em: 13 dez. 2013.

\section{MAUGHAN, R. J.; BURKE, L. M. Nutrição}

Esportiva. Porto Alegre: Artmed, 2004.

OLIVEIRA, D. F.; BRAVO, C. E. C.; TONIAL, I. B. Soro de leite: um subproduto valioso. Rev. Inst. Latic. Cândido Tostes, v.67, n.385, p. 64-71, 2012. Disponível em: <http://zip.net/bxty0k>. Acesso em: 13 dez. 2013.

OLIVEIRA, O. W.; PETROVICK, P. R. Secagem por aspersão (spray drying) de extratos vegetais: bases e aplicações. Rev. bras. farmacogn. [online], v.20, n.4, p. 641-650, 2010. Disponível em: <http://zip.net/ bdtywT >. Acesso em: 01 jul. 2014.

PACHECO, M. T. B. et al. Propriedades funcionais de hidrolisados obtidos a partir de concentrados proteicos de soro de leite. Ciênc. Tecnol. Aliment. [online], v.25, n.2, p. 333-338, 2005. Disponível em: <http://zip.net/bmtxWX>. Acesso em: 09 dez. 2013.

PASSOTTO, J. A. Proteínas lácteas: aplicações e funcionalidades. Food Ingredients Brasil, n.22, p. 80-82. Disponível em: <http://zip.net/bjtxXm>. Acesso em: 13 dez. 2013.

PEREIRA, I. O. Análise e otimização do processo de ultrafiltração do soro de leite para produção de concentrado proteico. 2009. 62 p. Dissertação de Mestrado - Programa de Pós-Graduação em Engenharia de Alimentos, Universidade Estadual do Sudoeste da Bahia, Itapetinga. Disponível em: <http://zip.net/bptyH4>. Acesso em: 13 dez. 2013. 


\section{SOBRE A AUTORA}

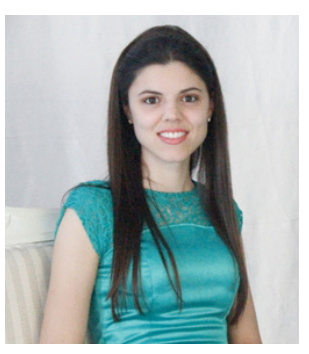

\section{Gabriela Bagio Luz}

Nutricionista graduada pela Universidade Comunitária da Região de Chapecó (UNOCHAPECÓ), pós-graduada em Alimentos Rev. Nutr., Campinas, v.16, n.3, p. 265-272, 2003. Disponível em: <http://zip.net/bctx24〉. Acesso em: 13 jan. 2014.

ROSA, E. D.; TSUKADA, M.; FREITAS, L. A. P. Secagem por atomização na indústria alimentícia: fundamentos e aplicações. Labmaq, 2006. Disponível em: <http://zip.net/bgtx1j>. Acesso em: 27 jun. 2014.

SGARBIERI, V. C. Propriedades fisiológicasfuncionais das proteínas do soro de leite. Rev. Nutr. [online]. 2004, v.17, n.4, p. 397-409. Disponível em: <http://zip.net/bwtxvd>. Acesso em: 18 jul. 2014.

SOUZA, M. A. Eficiência do processo de ultrafiltração seguido de biodigestão anaeróbia no tratamento de efluente de frigorífico de tilápia. 2010. 77 p. Tese de doutorado - Centro de Aquicultura, Universidade Estadual Paulista, Jaboticabal. Disponível em: <http://zip.net/bmtxWY>. Acesso em: 27 jun. 2014.

VIEIRA, A. P.; NICOLETI, J. F.; TELIS, V. R. N. Liofilização de fatias de abacaxi: avaliação da cinética de secagem e da qualidade do produto. Braz.J. Food Technol. [online]. 2012, v.15, n.1, p. 50-58. Disponível em: <http://zip.net/bltxwn>. Acesso em: 18 jul. 2014.

ZEISER, C. C.; SILVA, R. R. O Uso de Suplementos Alimentares entre os Profissionais de Educação Física Atuantes em Academias da Cidade de Florianópolis. Rev. Nutr. Pauta, São Paulo, v. 15, n. 86, 2007. Disponível em: <http://zip.net/bwtxvg>. Acesso em: 14 jan. 2014.

ZIEGLER, F. L. F. et al. Partial chemical and functional characterization of milk whey products obtained by different processes. Ciênc. Tecnol. Aliment. [online], v.32, n.1, p. 56-64, 2012. Disponível em: <http://zip.net/bstyhC>. Acesso em: 09 dez. 2013.

Data de recebimento: $12 / 10 / 2014$

Data de aprovação: 13/12/2016

Gama Filho (UGF). Pós-graduada em Tecnologia de Alimentos pela Universidade Estácio de Sá (UNESA). Atua na área de Saúde Pública como Agente do Programa Federal Núcleo de Apoio à SaúdedaFamília(NASF). Atuou como Nutricionista no SESI SC em Chapecó, nas funções de supervisão dos processos produtivos e Gestão da Qualidade e Segurança Alimentar em uma unidade industrial produtora de refeições. 